\title{
Title:
}

\section{The long life of a hemoclip}

\section{Authors:}

Isabel Garrido, Armando Peixoto, Guilherme Macedo

DOI: $10.17235 /$ reed.2022.8706/2022

Link: PubMed (Epub ahead of print)

Please cite this article as:

Garrido Isabel , Peixoto Armando, Macedo Guilherme. The long life of a hemoclip. Rev Esp Enferm Dig 2022. doi: 10.17235/reed.2022.8706/2022.

This is a PDF file of an unedited manuscript that has been accepted for publication. As a service to our customers we are providing this early version of the manuscript. The manuscript will undergo copyediting, typesetting, and review of the resulting proof before it is published in its final form. Please note that during the production process errors may be discovered which could affect the content, and all legal disclaimers that apply to the journal pertain. 
Title: "The long life of a hemoclip"

Authors: Isabel Garrido MD ${ }^{1,2}$, Armando Peixoto $\mathrm{MD}^{1,2}$, Guilherme Macedo MD PhD ${ }^{1,2}$

\section{Affiliations:}

${ }^{1}$ Gastroenterology and Hepatology Department, Centro Hospitalar Universitário de São João, Porto, Portugal

${ }^{2}$ World Gastroenterology Organization (WGO) Porto Training Center

\section{Corresponding author:}

Isabel Garrido MD

Gastroenterology and Hepatology Department, Centro Hospitalar Universitário de São João, Alameda Prof. Hernâni Monteiro, 4200-319 Porto, Portugal;

Tel: +351 22551 2100;

Email address: isabelmng@hotmail.com

\section{Acknowledgements:}

Conflict of interest statement: The authors have no disclosures to report.

Guarantor of the article: Isabel Garrido.

Author's contributions: Isabel Garrido drafted the manuscript. Isabel Garrido, Armando Peixoto and Guilherme Macedo have critically revised and finalized the manuscript. All authors have approved the final version of the manuscript.

Statement of Ethics: All rules of the local ethics committee were followed, preserving patient identity and confidentiality. 
An 87-year-old man, with frequent episodes of food impaction, underwent esophageal high-resolution manometry which revealed type I achalasia. Due to his advanced age and the presence of comorbidities, the injection of botulinum toxin was proposed and accepted by the patient. In June 2021, esophagogastroduodenoscopy revealed esophageal dilatation, with liquid and food retention and narrowing of the esophagogastric junction. An injection of 25 units of botulinum toxin diluted in $10 \mathrm{~mL}$ of saline was performed in each of the 4 lower esophageal sphincter quadrants, without complications. Interestingly, two rusty-looking hemoclips (Figure 1) were also seen near the esophagogastric junction, the site of a previous severe bleed. In fact, the patient had undergone a previous endoscopy in November 2016, 55 months earlier, when two metallic clips were applied due to a deep Mallory-Weiss tear during an episode of food impaction.

This is a rare case of asymptomatic hemoclip retention for more than 4 years after initial placement, remarkable for its rusty appearance. Hemostatic clips are a very common and effective intervention used by endoscopists ${ }^{1}$. However, they typically fall off on their own within 1-2 weeks ${ }^{2}$. The case presented here is an example that hemoclips can stay in place much longer than expected.

Currently, there are no guidelines for managing hemoclip retention and no established endoscopic method to remove embedded hemoclips without potential mucosal rupture. Long-term sequelae of hemoclip retention are uncertain. In our case, there were no noticeable clinical sequelae. 


\section{References:}

1. Gralnek IM, Stanley AJ, Morris AJ, et al. Endoscopic diagnosis and management of nonvariceal upper gastrointestinal hemorrhage (NVUGIH): European Society of Gastrointestinal Endoscopy (ESGE) Guideline - Update 2021. Endoscopy. 2021;53(3):300-332.

2. Ooi BP, Hassan MR, Kiew KK, et al. Case report of a hemostatic clip being retained for 2 years after deployment. Gastrointest Endosc. 2010; 72: 1315-1316. 


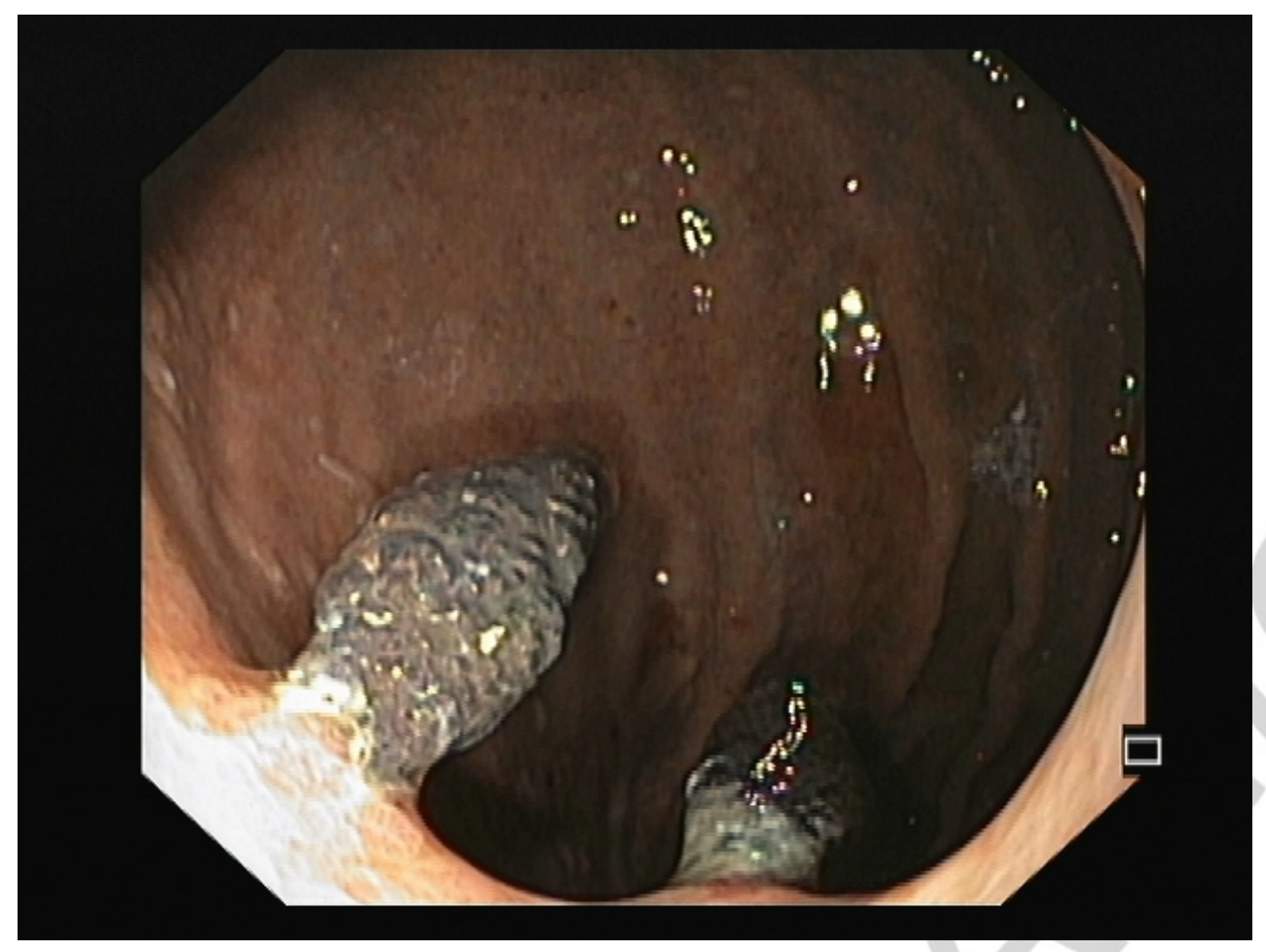

Figure 1 - Retained hemostatic clips near the cardioesophageal junction. 